\title{
PENERAPAN GRAPH-COLORING UNTUK REKOMENDASI PUSAT OLEH-OLEH KHAS SAMARINDA
}

\author{
Amelia Yusnita $^{1}$, Kusnandar ${ }^{2}$, Dewi Rosita ${ }^{3}$ \\ STMIK Widya Cipta Dharma ${ }^{1,2}$, Universitas Mulawarman ${ }^{3}$ \\ Jl. Prof. M. Yamin No. 25 Samarinda ${ }^{1,2}$, Jl. Muara Pahu Kampus \\ Gunung Kelua Samarinda ${ }^{3}$ \\ Sur-el : amel@wicida.ac.id ${ }^{1}$, kusnandar@wicida.ac.id², dew.rosita@gmail.com
}

\begin{abstract}
There are too many souvenir centers in Samarinda. Usually, it makes everyone confused to choose it, and it takes a long time to decide. This is one of the most common problems. In determining the location of the souvenir center, it is necessary to use place recommendations to save time. Therefore we need a system and method that can be applied to recommend a souvenir center. The souvenir center place recommendation application is made to help everyone in finding a souvenir center place with a choice of types of souvenirs. The method used is the Graph Coloring Method; with the application development method used is Waterfall consisting of data analysis, technology analysis, system analysis, information analysis and user analysis. The result of this research is that an application for determining the souvenir center, that application ion can recommend a center for souvenirs with the same choice of souvenirs. Users can input the type of souvenirs that they want, and then the application will recommend the center of the souvenirs by using a simple row and point coloring algorithm. After processing, the application will be able to display the results of recommendations for souvenir centers with the same type of souvenirs.
\end{abstract}

Keywords: Souvenir Center, Graph Coloring, Recommendations, Waterfall

\begin{abstract}
Abstrak : Banyaknya pusat oleh-oleh di Samarinda yang tersedia membuat setiap orang kebingungan dalam memilih tempat serta memerlukan waktu yang lama dalam menentukan, hal tersebut menjadi salah satu masalah yang sering muncul. Dalam menentukan tempat pusat oleh-oleh perlu digunakan rekomendasi tempat agar dapat menghemat waktu. Oleh karena itu dibutuhkan suatu sistem dan metode yang dapat diterapkan untuk merekomendasikan tempat pusat oleh-oleh. Aplikasi rekomendasi tempat pusat oleh-oleh dibuat untuk membantu setiap orang dalam mencari tempat pusat oleh-oleh dengan pilihan jenis oleh-oleh. Metode yang digunakan adalah Metode Pewarnaan Graf, dengan metode pengembangan aplikasi yang digunakan adalah Waterfall terdiri dari analisis data, analisis teknologi, analisis sistem, analisis informasi dan analisis user. Hasil dari penelitian ini adalah telah dibuat suatu aplikasi penentuan tempat pusat oleh-oleh yang dapat merekomendasikan tempat pusat olah-oleh dengan pilihan jenis oleholeh yang sama. User dapat memasukkan jenis oleh-oleh yang sesuai dengan keinginan kemudian aplikasi akan merekomendasikan tempat pusat oleh-oleh dengan menggunakan algoritma pewarnaan barisan sederhana pada titik. Setelah diproses maka aplikasi akan dapat menampilkan hasil rekomendasi tempat pusat oleh-oleh dengan jenis oleh-oleh yang sama.
\end{abstract}

Kata kunci: Pusat Oleh-oleh, Pewarnaan Graf, Rekomendasi, Waterfall

\section{PENDAHULUAN}

Samarinda merupakan ibukota dari wilayah Kalimantan Timur. Kota ini termasuk dalam Kota terbesar yang memiliki cukup banyak tempat wisata yang menarik [1]. Layaknya Kota yang ada di Indonesia, Kota
Samarinda terkenal akan nuansa alam yang indah nan rupawan [2]. Samarinda juga menawarkan aneka kuliner dan aneka kerajinan yang bisa dijadikan sebagai buah tangan [3],[4]. Banyak olahan makanan dan kerajinan yang sangat cocok dijadikan buah tangan bagi sahabat atau kerabat. Banyaknya pusat oleh-oleh di Samarinda yang tersedia membuat setiap orang 
kebingungan dalam memilih tempat serta memerlukan waktu yang lama dalam menentukan, hal tersebut menjadi salah satu masalah yang sering muncul. Dalam menentukan tempat pusat oleh-oleh perlu digunakan rekomendasi tempat agar dapat menghemat waktu [4],[5],[6],[7],[8].

Pada era zaman teknologi yang semakin canggih pada saat ini, setiap orang dengan mudah dalam melakukan sesuatu, termasuk dalam pencarian informasi pusat oleh-oleh di Samarinda [9]. Sumber informasi mengenai tempat pusat oleh-oleh yang didapatkan banyak, sehingga dapat memudahkan masyarakat dalam memilih. Akan tetapi informasi yang banyak dapat membuat masyarakat bingung dalam memilih tempat pusat oleh-oleh yang tepat untuk mereka kunjungi [7],[8]. Sehingga tidak efektif jika membutuhkan waktu yang lama dalam memilih tempat. Oleh karena itu suatu solusi yang tepat bisa digunakan setiap orang adalah aplikasi rekomendasi tempat pusat oleh-oleh. Aplikasi tersebut bisa memberikan berbagai macam pilihan terbaik dalam menentukan tempat pusat oleh-oleh yang akan mereka kunjungi.

Sistem Rekomendasi adalah suatu perangkat lunak yang berguna untuk membantu user dalam memberikan rekomendasi tempat pusat oleh-oleh ketika user dihadirkan dengan berbagai macam informasi dengan jumlah yang banyak [5],[11]. Selama kurun waktu 10 tahun terakhir berbagai pendekatan dan teknik yang baru sudah banyak diterapkan dalam sistem rekomendasi pada dunia industri maupun akademisi [6],[9],[10,[11]. Hampir semua area bisnis menggunakan konsep sistem rekomendasi secara luas, dimana pengguna membutuhkan informasi dalam menentukan suatu keputusan [5],[6],[11].

Adapun permasalahan dalam penelitian ini terletak pada bagaimana membuat suatu aplikasi untuk memutuskan tempat pusat oleholeh berdasarkan pilihan yang diinginkan. Berdasarkan permasalahan tersebut dapat diselesaikan dengan menggunakan salah satu metode yaitu Algoritma Pewarnaan Barisan Sederhana pada titik [12],[13]. Dengan menggunakan Algoritma Pewarnaan Barisan Sederhana pada titik akan memperoleh optimasi rekomendasi yaitu terdapat kondisi dimana terjadi kombinasi terbaik [4] untuk pasangan tempat pusat oleh-oleh serta pilihan ragam buah tangan secara keseluruhan untuk memutuskan tempat pusat oleh-oleh yang sesuai dengan masukan pengguna

Pewarnaan titik (vertex coloring) adalah memberi warna pada simpul-simpul suatu graf sedemikian sehingga tidak ada dua simpul bertetangga (berhubungan langsung) mempunyai warna yang sama [14]. Sedangkan Pewarnaan sisi (edge coloring) adalah memberi warna berbeda pada sisi yang berhubungan langsung sehingga tidak ada dua sisi yang bertetangga mempunyai warna yang sama [14],[15]. Jadi pada intinya Graf terbentuk dari himpunan pasangan (V,E) dimana V adalah himpunan tidak kosong dari simpul-simpul (vertices) dan $\mathrm{E}$ adalah himpunan sisi (edges) yang menghubungkan sepasang simpul [15].

Penelitian ini bertujuan untuk membangun suatu aplikasi penentuan tempat pusat oleh-oleh berbasis desktop untuk mencari 
tempat pusat oleh-oleh dengan pilihan jenis oleholeh yang sama, dengan mengimplementasikan Graph-Coloring untuk Rekomendasi Pusat OlehOleh Khas Samarinda. Diharapkan hasil penelitian ini dapat membantu orang-orang khususnya pendatang untuk memilih tempat oleh-oleh yang tepat dari lokasinya berada.

\section{METODOLOGI PENELITIAN}

Metode pengembangan sistem dalam penelitian ini adalah model air terjun (Waterfall) adalah model klasik yang bersifat sistematis, berurutan dalam membangun software [16],[17]. Pada model ini dapat memungkinkan pemecahan pengembangan yang rumit menjadi beberapa langkah logis (desain, kode, pengujian, dan seterusnya) yang pada akhirnya akan menjadi produk akhir siap pakai [16]. Fase-fase model waterfall dapat dilihat pada gambar 1 .

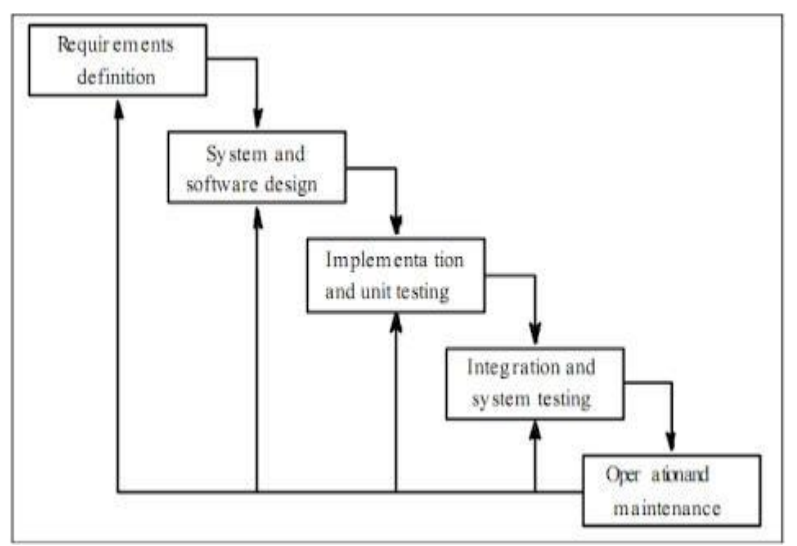

Gambar 1. Fase-Fase Dalam Waterfall Model

Adapun tahapan yang terdapat dalam waterfall model adalah sebagai berikut [17]:

1. Requirements Definition, adalah proses analisis kebutuhan secara lengkap dan didefinisikan kebutuhan yang harus dipenuhi oleh aplikasi yang akan dibangun. Fase ini harus dikerjakan secara lengkap untuk bisa menghasilkan desain yang lengkap.

2. System and Software Design, adalah pembuatan desain aplikasi sebelum proses coding. Desain Sistem membantu dalam menentukan perangkat keras (hardware) dan sistem persyaratan yang lain serta membantu dalam mendefinisikan arsitektur sistem secara keseluruhan.

3. Implementation and Unit Testing, merupakan pembuatan desain aplikasi diterjemahkan ke dalam kode-kode dengan menggunakan bahasa pemrograman yang telah ditentukan. Aplikasi yang dibangun langsung diuji baik secara unit.

4. Integration and System Testing, merupakan penyatuan unit-unit aplikasi kemudian diuji secara keseluruhan (system testing).

5. Operation and Maintenance adalah tahap aplikasi dioperasikan pada lingkungannya dan melakukan pemeliharaan, seperti penyesuaian atau perubahan.

\section{HASIL DAN PEMBAHASAN}

Flowchart Algoritma Pewarnaan Barisan Sederhana Pada Titik tertera dapat dilihat dalam gambar 2. 


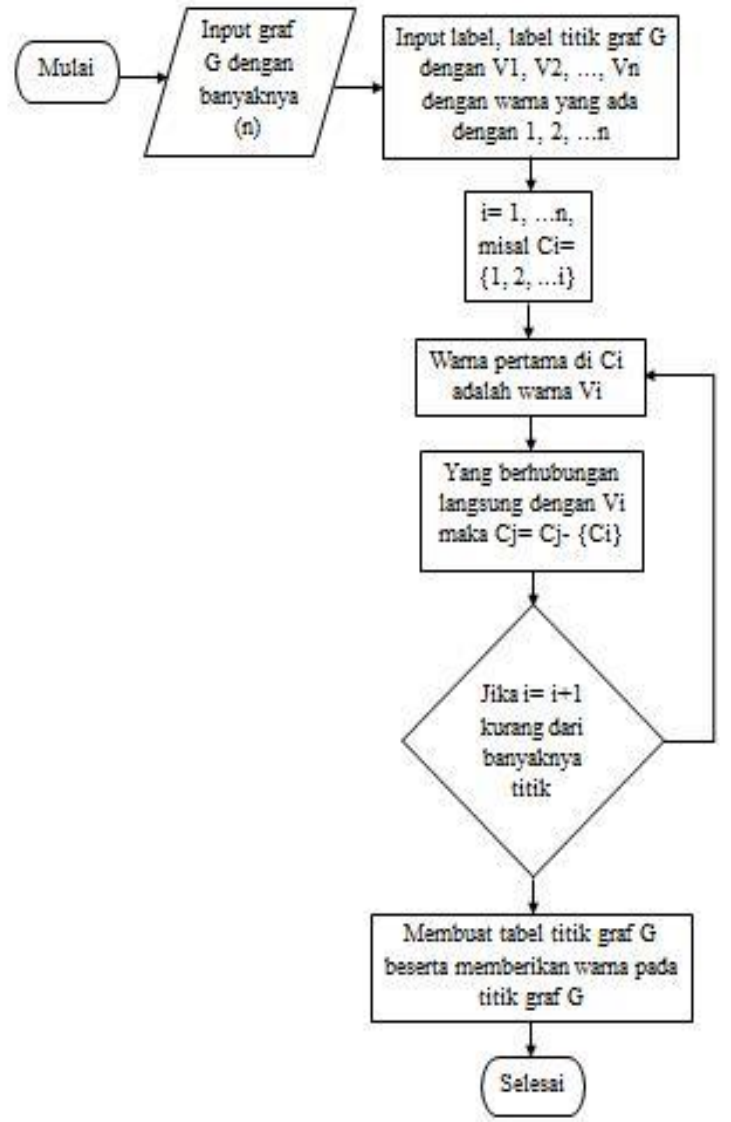

\section{Gambar 2. Flowchart Algoritma Pewarnaan}

\section{Barisan Sederhana Pada Titik}

Pada gambar 2, merupakan alur flowchart dari sistem rekomendasi yang menggunakan metode pewarnaan graf pada titik. Dimulai dari memasukan banyaknya $n$ yang ada pada graf $\mathrm{G}$ dan dilanjutkan pada step-step sebagai berikut:

Langkah ke-1:

1. Memberikan label kepada setiap titik yang ada pada graf $\mathrm{G}$ dengan label V1, V2, ...Vn.

2. Warna yang disediakan sama dengan banyaknya titik yang ada pada graf $\mathrm{G}$.

Langkah ke-2:

1. i sama dengan banyaknya titik yang ada pada graf G.

2. $\mathrm{Ci}$ adalah daftar warna yang disediakan untuk memberikan warna pada graf $\mathrm{G}$.

Langkah ke-3: $\mathrm{i}=1$ (titik pertama pada vertex) $\mathrm{V} 1$.
Langkah ke-4:

Warna pertama yang disediakan pada step 2 (Ci), maka warna tersebut adalah warna yang akan diberikan pada Vi.

Langkah ke-5:

1. Yang berhubungan langsung dengan titik yang sedang dieksekusi, maka titik yang berhubungan tidak dapat menggunakan warna yang sama dengan titik yang sedang dieksekusi.

2. Didapat $i=i+1$. Apabila hasil i lebih dari banyaknya titik yang ada pada graf $\mathrm{G}$ maka lanjut pada step 6, jika kurang atau sama dengan titik yang ada pada graf $G$ maka kembali melakukan step 4.

Langkah ke-6:

Membuat tabel hasil pewarnaan titik pada graf G.

Proses pewarnaan graf antara vertex tempat pusat oleh-oleh dan edge jenis oleh-oleh untuk menentukan tempat pusat oleh-oleh dengan jenis oleh-oleh yang sama. Salah satu digambarkan pada Gambar 3, contoh graf pencarian oleh amplang.

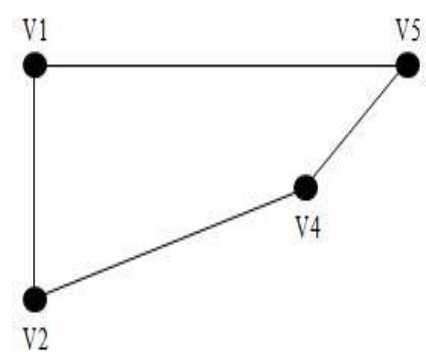

Gambar 3. Graf Jenis Amplang

Keterangan gambar 3.

V1: Jukut Oleh-Oleh Samarinda

V2: UKM Center

V4: East Kalimantan Center

V5: Kampung Amplang 
Selanjutnya dapat dilihat pada gambar 4, $5,6,7$, dan 8 adalah contoh pencarian graf oleholeh kaos khas Samarinda, Sarung Samarinda, kue keminting, souvenir Dayak, dan kue ilat sapi

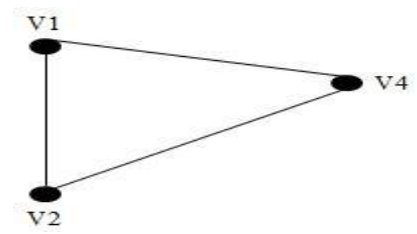

\section{Gambar 4. Graf Jenis Kaos Samarinda}

Keterangan gambar 4.

V1: Jukut Oleh-Oleh Samarinda

V2: UKM Center

V4: East Kalimantan Center

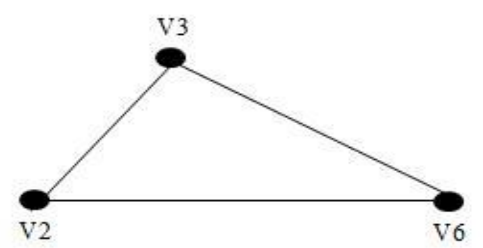

\section{Gambar 5. Graf Jenis Sarung Samarinda}

Keterangan gambar 5.

V2: UKM Center

V3: Fitriah

V6: Citra Niaga

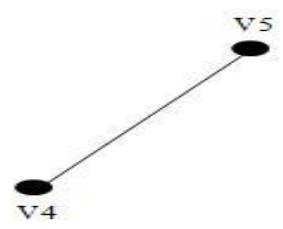

\section{Gambar 6. Graf Jenis kue Keminting}

Keterangan gambar 6.

V4: East Kalimantan Center

V5: Kampung Amplang

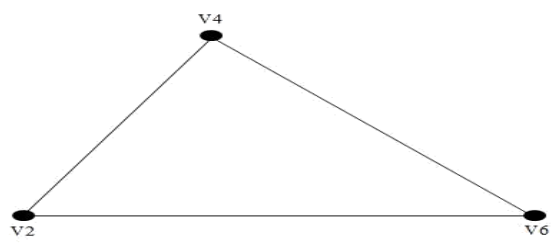

Gambar 7. Graf Jenis Souvenir Dayak

Keterangan gambar 7.

V2: UKM Center
V4: East Kalimantan Center

V6: Citra Niaga

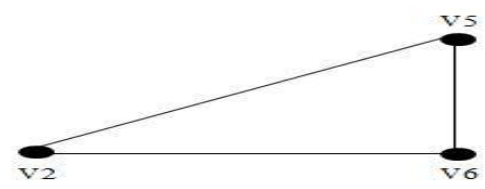

Gambar 8. Graf jenis kue ilat sapi

Keterangan gambar 8.

V2: UKM Center

V5: Kampung Amplang

V6: Citra Niaga

Dapat dilihat pada gambar 9 adalah graf tempat pusat oleh-oleh dan Jenis oleh-oleh, dijabarkan sebagai berikut:

V1: Jukut Oleh-oleh Samarinda dengan jenis Kaos Samarinda, Amplang

V2: UKM Center dengan jenis Amplang, batik, Souvenir, Sarung

V3: Firtiah dengan jenis sarung, kaos, Souvenir, batik

V4: East Kalimantan Center dengan jenis Amplang, batik, Souvenir, Sarung, makanan khas Samarinda

V5: Kampung amplang dengan jenis amplang dan makanan khas Samarinda

V6: Citra Niaga dengan jenis sarung, kaos, souvenir, batik, makanan khas Samarinda

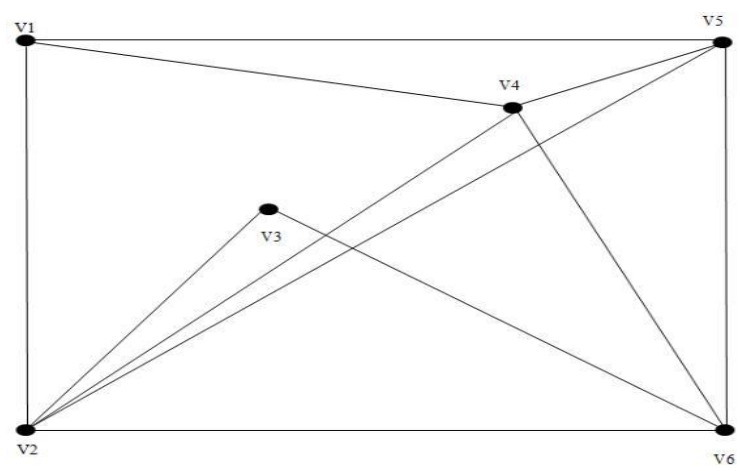

Gambar 9. Graf Tempat pusat oleh-oleh dan Jenis oleh-oleh 
Edge: Jenis pilihan oleh-oleh 1= Orange, $2=$ Abu-Abu, $3=$ Merah, $4=$ Biru, 5= Hitam, $6=$ Hijau

Diketahui:

1. Titik yang berhubungan langsung dengan V1 adalah V2, V4, V5

2. Titik yang berhubungan langsung dengan $\mathrm{V} 2$ adalah V1, V3, V4, V5, V6

3. Titik yang berhubungan langsung dengan V3 adalah V2, V6

4. Titik yang berhubungan langsung dengan V4 adalah V1, V2, V5, V6

5. Titik yang berhubungan langsung dengan V5 adalah V1, V2, V4, V6

6. Titik yang berhubungan langsung dengan V6 adalah V2, V3, V4, V5

Langkah-Langkah Penyelesaian:

Step 1: Label warna yang tersedia adalah 1, 2, $3,4,5,6$

Step 2: $\mathrm{C} 1=\{1\}, \mathrm{C} 2=\{1,2\}, \mathrm{C} 3=\{1,2,3\}$, $\mathrm{C} 4=\{1,2,3,4\}, \mathrm{C} 5=\{1,2,3,4,5\}$, $\mathrm{C} 6=\{1,2,3,4,5,6\}$

Step 3: $\mathrm{i}=1$

Step 4: 1 adalah warna pertama di C1, Jadi warna titik V1 dengan warna 1

Step 5: Titik yang berhubungan langsung dengan titik yang di V1 adalah V2, V4, V5

$\mathrm{C} 2=\{1,2\}-\{1\}=\{2\}$

$\mathrm{C} 4=\{1,2,3,4\}-\{1\}=\{2,3,4\}$

$\mathrm{C} 5=\{1,2,3,4,5\}-\{1\}=\{2,3,4,5\}$

$\mathrm{i}=1+1=2$

Step 4: $\mathrm{V} 2=2$

Step 5: Titik yang berhubungan langsung dengan titik yang ada di V2 adalah V3, V5, V4, V6 C3 $=\{1,2,3\}-\{2\}=\{1,3\}$
$\mathrm{C} 5=\{2,3,4,5\}-\{2\}=\{3,4,5\}$

$\mathrm{C} 4=\{2,3,4\}-\{2\}=\{3,4\}$

$\mathrm{C} 6=\{1,2,3,4,5,6\}-\{2\}=\{1,3,4,5,6\}$

$\mathrm{i}=2+1=3$

Step 4: V3= 1

Step 5: Titik yang berhubungan langsung dengan titik yang ada di V3 adalah V6

$\mathrm{C} 6=\{1,3,4,5,6\}-\{1\}=\{3,4,5,6\}$

$\mathrm{i}=3+1=4$

Step 4: V4= 3

Step 5: Titik yang berhubungan langsung dengan titik yang ada di V4 adalah V5, V6

$\mathrm{C} 5=\{3,4,5\}-\{3\}=\{4,5\}$

$\mathrm{C} 6=\{3,4,5,6\}-\{3\}=\{4,5,6\} ; \mathrm{i}=4+1=5$

Step 4: V5= 4

Step 5: Titik yang berhubungan langsung dengan titik di V5 adalah V4, V6 Kalimantan Center, kampung amplang dan edge: jenis

$\mathrm{C} 4=\{3,4\}-\{4\}=\{3\}$ pilihan oleh-oleh Amplang.

$\mathrm{C} 6=\{4,5,6\}-\{4\}=\{5,6\}$

$\mathrm{i}=5+1=6$

Step 4: V6=5

Step 5: Titik yang berhubungan langsung dengan titik yang ada di V6 adalah V3, V5

$\mathrm{C} 3=\{1,3\}-\{5\}=\{1,3\}$

$\mathrm{C} 5=\{4,5\}-\{5\}=\{4\}$

$\mathrm{i}=6+1=7$

Step 5: Hasil i lebih dari banyaknya titik yang ada pada graf maka lanjut pada step 6

Maka didapatkan hasil titik-titik $\mathrm{G}$ dan warnanya dijabarkan pada tabel 1 . 
Tabel 1. Titik-titik $\mathbf{G}$ dan warnanya

\begin{tabular}{crrrrrr}
\hline $\boldsymbol{V}(\boldsymbol{G})$ & $\boldsymbol{V}_{\boldsymbol{1}}$ & $\boldsymbol{V}_{\mathbf{2}}$ & $\boldsymbol{V}_{\mathbf{3}}$ & $\boldsymbol{V}_{\mathbf{4}}$ & $\boldsymbol{V}_{5}$ & $\boldsymbol{V}_{\mathbf{6}}$ \\
\hline Warna Vi & 1 & 2 & 1 & 3 & 4 & 5
\end{tabular}

Pada gambar 10. adalah hasil dari pewarnaan antara vertex tempat dan edge jenis. Adapun hasil dari pewarnaan graf untuk rekomendasi tempat pusat oleh-oleh sesuai dengan jenis oleh-oleh yang ditawarkan yaitu ada 5 warna yang didapatkan terlihat pada gambar 10., 5 warna yang didapatkan pada graf $\mathrm{G}$ pada rekomendasi ini digunakan untuk menentukan jenis pilihan oleh-olehnya. Jadi, 5 warna adalah 5 tempat pusat oleh-oleh yang mempunyai jenis pilihan yang sama. Untuk rekomendasi tempat pusat oleh-oleh ini, pada warna yang sama maka tempat pusat oleh-oleh tersebut mempunyai jenis pilihan yang berbeda.

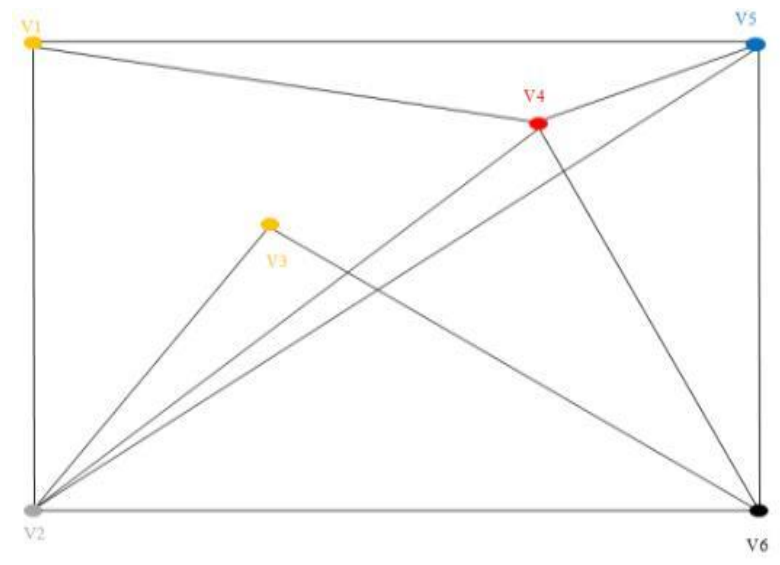

\section{Gambar 10. Hasil Pewarnaan Graf}

Gambar 11 adalah hasil dari pewarnaan antara vertex : jukut oleh-oleh Samarinda, UKM Center, East kalimantan Center, kampung amplang dan edge: jenis pilihan oleh-oleh Amplang.

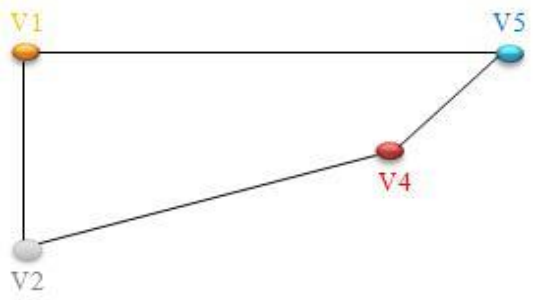

\section{Gambar 11. Hasil Pewarnaan Graf jenis}

Amplang

Gambar 12 adalah hasil dari pewarnaan antara vertex: Jukut oleh-oleh Samarinda, UKM Center, East Kalimantan Center dan edge: jenis oleh-oleh kaos Samarinda.

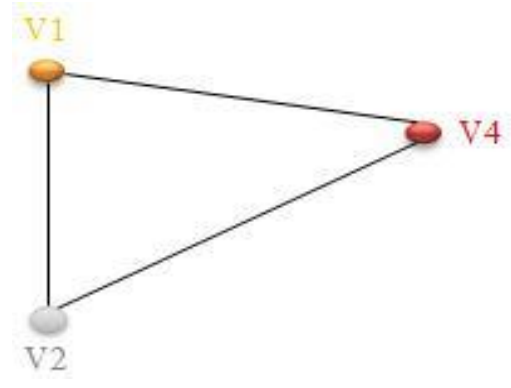

\section{Gambar 12. Hasil Pewarnaan Graf jenis kaos Samarinda}

Gambar 13 adalah hasil dari pewarnaan antara vertex: UKM Center, Fitriah, Citra Niaga dan edge: jenis oleh-oleh Sarung Samarinda

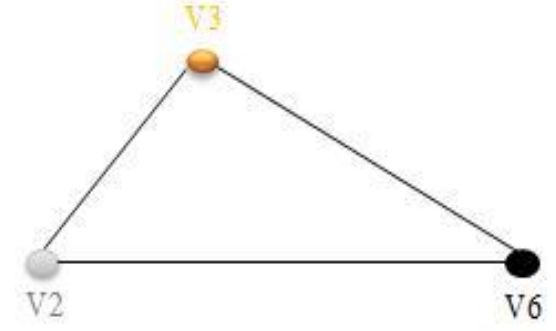

\section{Gambar 13. Hasil Pewarnaan Graf jenis Sarung Samarinda}

Dapat dilihat pada Gambar 14, merupakan hasil dari pewarnaan antara vertex: East Kalimantan, Kampung Amplang dan edge: jenis oleh-oleh kue keminting. 


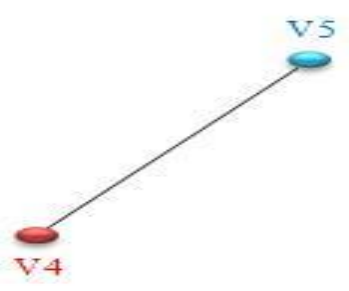

Gambar 14. Hasil Pewarnaan Graf Jenis Kue Keminting

Pada gambar 15, menunjukkan hasil dari pewarnaan antara vertex: UKM Center, East Kalimantan Center, Citra Niaga dan edge: menu jenis oleh-oleh Souvenir Dayak.

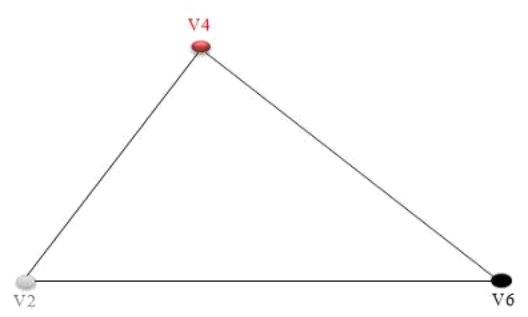

\section{Gambar 15. Hasil Pewarnaan Graf jenis} Souvenir Dayak

Terakhir pada gambar 16 adalah hasil dari pewarnaan antara vertex: UKM Center, Kampung Amplang, Citra Niaga dan edge: jenis oleh-oleh kue ilat sapi.

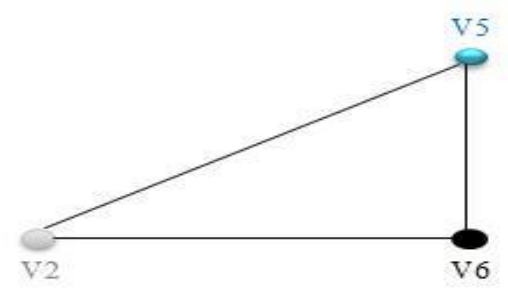

\section{Gambar 16. Hasil Pewarnaan Jenis Kue Ilat}

Sapi

Dari hasil perhitungan secara manual di atas, vertex yang saling terhubung mempunyai jenis oleh-oleh yang sama. Hasil tersebut sesuai dengan pewarnaan graf yang dihitung menggunakan sistem rekomendasi pusat oleholeh yang dibangun. Berikut ini pada tabel 2, menunjukkan hasil rekomendasi setiap jenis pilihan oleh-olehnya

Tabel 2. Hasil Peringkat Rekomendasi

\begin{tabular}{clc}
\hline $\begin{array}{c}\text { Jenis } \\
\text { Oleh-oleh }\end{array}$ & \multicolumn{1}{c}{$\begin{array}{c}\text { Tempat } \\
\text { Pusat Oleh-Oleh }\end{array}$} & Peringkat \\
\hline \multirow{4}{*}{ Amplang } & Jukut Oleh-oleh & 1 \\
& Samarinda & \\
& UKM Center & 2 \\
& East Kalimantan Center & 3 \\
& Kampung Amplang & 4 \\
& Jukut Oleh-oleh & 1 \\
Kaos & Samarinda & \\
Samarinda & UKM Center & 2 \\
& East Kalimantan Center & 3 \\
Sarung & UKM Center & 1 \\
Samarinda & Fitriah & 2 \\
Kue & Citra Niaga & 3 \\
Keminting & East Kalimantan Center & 1 \\
Souvenir & UKM Center & 2 \\
Dayak & East Kalimantan Center & 2 \\
& Citra Niaga & 3 \\
Kue ilat & UKM Center & 1 \\
Sapi & Kampung Amplang & 2 \\
& Citra Niaga & 3 \\
\hline
\end{tabular}

Dari hasil semua rekomendasi di Tabel 2, dapat disimpulkan UKM Center adalah pusat oleh-oleh yang terlengkap dibandingkan tempat oleh-oleh lainnya.

\section{KESIMPULAN}

Penerapan metode pewarnaan graf untuk melakukan rekomendasi tempat pusat oleh-oleh di Kota Samarinda dilakukan dengan menggunakan metode pengembangan sistem Model Air Terjun (Waterfall). Dengan menerapkan metode pewarnaan graf untuk 
merekomendasikan tempat pusat oleh-oleh, pengguna dalam hal ini pendatang dan turis dapat dengan mudah mencari oleh-oleh yang diinginkan dengan cepat di lokasi yang terlengkap. Diharapkan penelitian selanjutnya, dikarenakan dalam aplikasi ini tidak memperhitungkan tingkat popularitas tempat dan jarak terdekat maka diharapkan untuk dapat menambahkan tingkat popularitas tempat dalam aplikasi serta mengembangkan aplikasi ini dengan melihat jarak terdekat/sistem zonasi tempat yang direkomendasikan.

\section{UCAPAN TERIMA KASIH}

Publikasi ini dibiayai oleh Direktorat Riset dan Pengabdian Masyarakat Direktorat Jenderal Penguatan Riset dan Pengembangan Kementerian Kementerian Pendidikan, Kebudayaan, Riset, dan Teknologi Republik Indonesia dengan Kontrak Penelitian Tahun Anggaran 2021.

\section{DAFTAR PUSTAKA}

[1] Nursobah \& P. Pahrudin. Cahaya di Langit Samarinda. Scopindo Media Pustaka. 2020

[2] W.G. Mulawarman, A. Rokhmansyah. Ketahanan Keluarga Studi Kasus di Kelurahan Mesjid Kota Samarinda. Istana Agency. 2019

[3] I. Sudarmayasa, M. Noor, and S. Uhai, "Standarisasi Produk Rumah Makan Khas Samarinda Di Kota Samarinda", Sebatik, vol. 23, no. 2, pp. 633-640, Dec. 2019.

[4] W. Widiyatni, et al. Penerapan Pewarnaan Graf Untuk Menentukan Wisata Kuliner Di Samarinda. Jurnal Ilmiah MATRIK, 22.2: 177-186. 2020.

[5] Himawan, H., Putri, D. G., \& Kaswidjanti, W. Metode Lexicon Based Dan Support Vector Machine Untuk Menganalisis Sentimen Pada Media Sosial Sebagai
Rekomendasi Oleh-Oleh Favorit. In Seminar Nasional Informatika (SEMNASIF) (Vol. 1, No. 1). 2018.

[6] Widiyana, R. Implementasi Metode CaseBased Reasoning Untuk Rekomendasi Tempat Oleh-Oleh Di Kota Malang Berbasis Android. JATI (Jurnal Mahasiswa Teknik Informatika), 1(1), 763-769. 2017.

[7] Wibowo, A. T. Pembuatan Aplikasi ECommerce Pusat Oleh-Oleh Khas Pacitan Pada Toko Sari Rasa Pacitan. IJNSIndonesian Journal on Networking and Security, 2(4). 2012.

[8] Sylfania, D. Y., Perkasa, E. B., \& Juniawan, F. P. Rancang Bangun Sistem Informasi Geografis Pemetaan Toko OlehOleh dan Souvenir Khas Bangka di kota Pangkalpinang. Jurnal Teknik Informatika. 2017

[9] Jayanti, G. Penerapan E-Commerce Dalam Proses Komunikasi Pemasaran Di Toko East Kalimantan Center Samarinda. E Journal Ilmu Komunikasi, 2(3), 219228. 2014

[10] Simanjuntak, O. S., Santosa, B., \& Prasetyo, M. B. Pertimbangan Pembelian Oleh-oleh Pada Rute Perjalananan Wisatawan Menggunakan Technique for Others Preference by Similarity to Ideal Solution (TOPSIS). Telematika: Jurnal Informatika dan Teknologi Informasi, 14(1), 52-61. 2017

[11] Komaruddin, A., Susilo, B., \& Setiawan, Y. Perancangan Sistem Rekomendasi Pemilihan Cinderamata Khas Bengkulu Berbasis E-Marketplace. Rekursif: Jurnal Informatika, 7(1).

[12] W. Fokkink, Distributed Algorithms: An Intuitive Approach. United States, MIT Press, 2018.

[13] M. Molloy \& B. Reed, Graph Colouring and the Probabilistic Method. Germany, Springer Berlin Heidelberg, 2013.

[14] P. Zhang, Color-Induced Graph Colorings. Germany, Springer International Publishing, 2015.

[15] F. Daniel, P. N. L. Taneo. Teori Graf. Deepublish. 2019

[16] I. Sommerville, Software Engineering. Netherlands, Pearson, 2015.

[17] F. H. Utami dan Asnawati. Rekayasa Perangkat Lunak. Deepublish. 2015 